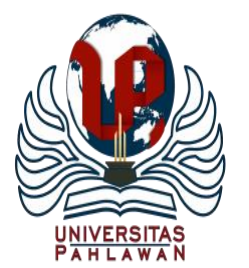

Jurnal Abdidas Volume 2 Nomor 3 Tahun 2021 Halaman 566-572

JURNAL ABDIDAS

http://abdidas.org/index.php/abdidas

\title{
Peningkatan Produktifitas dan Pemasaran UMKM dengan Teknologi Informasi dan Manajemen Keuangan untuk Memacu Perekonomian yang Lebih Baik
}

\author{
Nur Hudha Wijaya ${ }^{1}$, Puspita Dewi Wulaningrum ${ }^{2}$, Wisnu Kartika ${ }^{3}$ \\ Teknologi Elektrmedis, Program Vokasi, Universitas Muhammadiyah Yogyakarta, Indonesia ${ }^{1,3}$ \\ Akuntansi, Program Vokasi, Universitas Muhammadiyah Yogyakarta, Indonesia ${ }^{2}$ \\ E-mail : nurhudhawijaya@umy.ac.id ${ }^{1}$ puspitadewiwulaningrum@ vokasi.umy.ac.id ${ }^{2}$ wisnu2007@umy.ac.id ${ }^{3}$
}

\begin{abstract}
Abstrak
Masa pandemik ini penurunan finansial kelompok Usaha Mikro Kecil Menengah (UMKM). Permasalahan yang dialami para pelaku UMKM adalah kurangnya promosi dan branding, serta sistem pengolahan keuangan yang masih konvensional tidak tercatat. UMKM tersebut adalah bidang usaha emping melinjo dan gethuk. Jika ada promosi yang baik, maka informasi produk olahan di Wirokerten ini akan lebih mendorong pertumbuhan ekonomi dan peluang kerja bagi masyarakat. Dengan adanya standar laporan keuangan tersebut tentu dapat menjadi dokumentasi bagi UMKM. Hal ini akan menunjang kekuatan ekonomi rakyat yang semakin kokoh di masa depan karena usaha-usaha kecil ini memiliki harapan untuk berkembang menjadi lebih besar. Maka tujuan yang dicapai dalam progam ini adalah menerapkan teknologi dan keterampilan para pelaku UMKM agar memiliki keterampilan atau kemampuan tentang praktik pemanfaatan teknologi informasi dan pembukuan yang baik. Adapun metode yang digunakan adalah pembelajaran dan aplikasi berbasis partisipatif. Pada hasil evaluasi mitra sudah mampu melakukan branding dengan teknologi informasi dan pembukuan, pencatatan dan pelaporan keuangan sesuai dengan standar sesuai urutan yang sudah disampaikan. Kata kunci: teknologi informasi, pembukuan, UMKM, usaha mikro kecil menengah
\end{abstract}

\section{Abstract}

During this pandemic period, the financial decline of micro, small and medium enterprises (MSMEs). The problems experienced by MSME actors are the lack of promotion and branding, as well as the conventional financial processing system that is not recorded, the MSMEs are the emping melinjo and gethuk business fields. If there is a good promotion then the information on processed products in this wirokerten will further encourage economic growth and job opportunities for the community. With the standard financial statements, it can certainly be a documentation for MSMEs. This will support the people's economic strength which will be stronger in the future because these small businesses have the hope of developing into a bigger one. So the goal achieved in this program is to apply the technology and skills of MSME actors so that they have the skills or abilities regarding the practice of using information technology and good bookkeeping. The method used is participatory-based learning and application. In the evaluation results, partners have been able to do branding with information technology and bookkeeping, recording and financial reporting in accordance with standards in the order that has been submitted.

Keywords: information technology, bookkeeping, UMKM, micro, small and medium enterprises

Copyright (c) 2021 Nur Hudha Wijaya, Puspita Dewi Wulaningrum, Wisnu Kartika

$\triangle$ Corresponding author

Address : Universitas Muhammadiyah Yogyakarta

Email : nurhudhawijaya@umy.ac.id

ISSN 2721-9224 (Media Cetak)

DOI $\quad:$ https://doi.org/10.31004/abdidas.v2i3.319

ISSN 2721- 9216 (Media Online) 
567 Peningkatan Produktifitas dan Pemasaran UMKM dengan Teknologi Informasi dan Manajemen Keuangan untuk Memacu Perekonomian yang Lebih Baik- Nur Hudha Wijaya, Puspita Dewi Wulaningrum, Wisnu Kartika

DOI: https://doi.org/10.31004/abdidas.v2i3.319

\section{PENDAHULUAN}

Emping melinjo merupakan salah satu produk inovasi rintisan usaha mikro kecil menengah dengan nama usaha dagang "Alvin Putra", yang beralamat di Dusun Glondong 05, Wirokerten, Banguntapan, Bantul, DIY.yang di gagas oleh Ibu Sujarwati. UMKM ini bergerak di bidang usaha dagang pembuatan dan penjualan produk inovasi berbahan melinjo yang diolah menjadi keripik/emping. Usaha ini beroperasi sudah 3 tahun lamanya yang berawal dari keterpurukan ekonomi, dengan potensi yang dimiliki ibu Sujarwati memulai usaha pembuatan emping melinjo ini. Usaha emping melinjo Alvin Putra ini mempekerjakan 1 orang, sehingga tidak menuntut kemungkinan dapat berkembang dan membantu masyarakat di wilayah tersebut untuk mengembangkan emping melinjo (Ahmad Farki, Imam Baihaqi, 2017). Emping melinjo juga merupakan rintisan usaha inovasi mikro(Hudhawijaya et al., 2020). Emping ini merupakan produk inovasi dengan pemanfaatan bahan yang terlihat di depan mata karena banyak pohon melinjo di wilayah Wirokerten. Selain mengenalkan kepada masyarakat akan pentingnya inovasi terhadap bahan-bahan yang akan menjadi produk yang luar biasa (Ariani Kartika Suwignyo1, Justinus Andjarwirawan2, n.d.). Selain untuk meningkatkan produk inovasi, usaha dagang ini juga dapat membantu masyarakat di sekitar khususnya ibuibu dalam peningkatan ekonomi (Beben Sutara, 2017). Proses produksi emping melinjo ini sangat sederhana, dengan bermodal palu dan karpet sebagai penaham melinjo yang dipukul sehingga menjadi pipih (Wijaya, n.d.). Dengan sistem tersebut, tentunya belum bisa memenuhi target pasar yang cukup banyak, emping melinjo produk dari Ibu Sujar ini diambil oleh toko-toko jajanan dan oleh-oleh, maka dari itu sering kewalahan melayani pesanan, sekaligus tidak memiliki nama resmi ketika produk empingnya diambil oleh pemilik toko (merk) Alvin Putra hanya sebatas nama di pedukuhan itu saja, selain itu Ibu Sujar tidak pernak mencatat berapa bungkus emping melinjo dan berapa rupiah yang sudah dihasilkan, yang penting esok hari ada uang untuk beli bahan dan bisa produksi lagi. Tak jarang hal yang dilakukan oleh Ibu Sujar dilakukan pula oleh UMKM yang lain, tanpa disadari, usaha menjadi susah untuk maju, dengan permasalahan tersebut pengabdian ini diharapkan mampu menaikkan nama usaha UMKM ini menjadi lebih baik disertai kebiasaan melakukan pembukuan yang lebih baik.

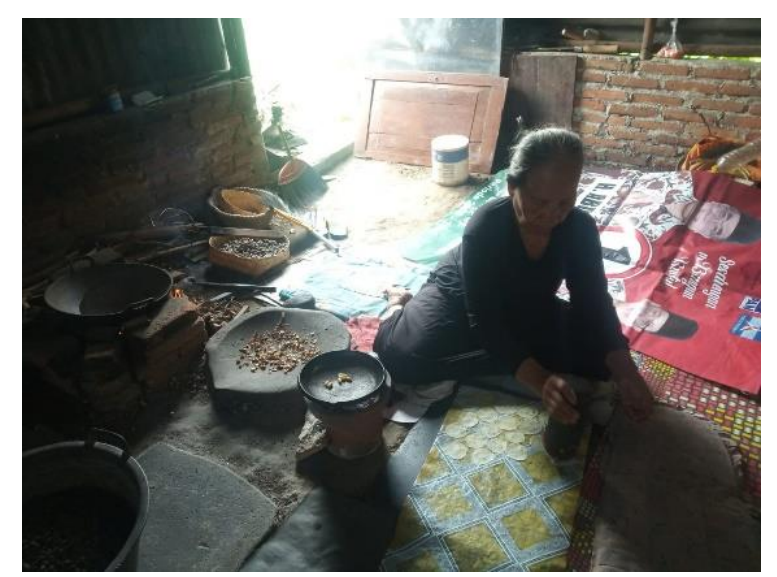

Gambar 1. Proses Pembuatan Emping Melinjo

$$
\text { Pengeringan emping melinjo ini }
$$
menggunakan sistem manual yaitu dijemur di bawah terik matahari. Jika musim penghujan akan mengalami kendala yaitu emping yang sudah 
568 Peningkatan Produktifitas dan Pemasaran UMKM dengan Teknologi Informasi dan Manajemen Keuangan untuk Memacu Perekonomian yang Lebih Baik- Nur Hudha Wijaya, Puspita Dewi Wulaningrum, Wisnu Kartika

DOI: https://doi.org/10.31004/abdidas.v2i3.319

ditumbuk akan menumpuk dan hasil kurang maksimal karena kering tersapu angin berhari-hari (Gary Hans1, Justinus Andjarwirawan2, n.d.). Maka dari itu salah satu penerapan teknologi yaitu dibuatlah oven pengering untuk emping melinjo. Hal pendukung lainya adalah pembuatan stiker yang tertempel di bungkus kemasan (Sugiyanto, 2018), yang selama ini hanya kertas biasa yang di Photocopy dengan label merek. Hal tersebut kurang menarik calon konsumen, maka dari itu pengembangan yang diberikan adalah dengan merubah label tersebut menjadi stiker yang tertempel di bungus plastik kemasan emping melinjo (Qonita et al., 2016).

Mitra yang kedua adalah Ibu Romidah, beliau selaku pelaku usaha UMKM pembuatan gethuk, dan usaha ini diberi nama "Aneka Gethuk", yang beramalatkan di Dusun Mutihan RT. 02 Wirokerten, Banguntapan, Bantul Yogyakarta. Menurut hasil wawancara pengabdi kepada pelaku usaha yaitu Ibu Romidah merupakan mantan karyawan pada perusahaan pengrajin perak di Kota Gede Yogyakarta, setiap hari berangkat pagi pulang petang, sampai tidak bisa memperhatikan buah hatinya yang masih kecil, tak terasa sudah berusia SD, berawal dari situ, ibu Romidah memutuskan untuk mengundurkan diri dari perusahaan perak tersebut, dan ikut berdagang gethuk bersama kakak kandungnya, seiring berjalannya waktu, setahun 2 atau 3 kali tiap acara di kelurahan, disajikan makanan-makanan tradisional diantaranya gethuk, berawal dari situ Ibu Romidah memutuskan untuk memproduksi sendiri usaha barunya di bidang jajanan tradisional yaitu Gethuk (Aprih Santoso1, Teguh Ariefiantoro2, 2017). Berjalannya waktu pandemi mulai kabarkan oleh pemerintah, acara di kelurahan semakin dibatasi, Ibu Romidah mengambil keputusan untuk menjual produk gethuknya di kaki lima daerah Jl. Imogiri Timur, tepatnya di depan SMK Pleret, telah disadari jauhjauh hari, Ibu Romidah hanya memproduksi sedikit, karena pembeli menurun drastis karna pandemi ini, hanya dengan cara konvensional ini gethuk kurang diminati (Endang Kartini Panggiarti, 2005), karena dianggap makanan kampung, keluhan dari Ibu Romidah yaitu terkendala pada pemasaran beserta perlakuan pengolahan secara konvensional (Sisilia Pujiatmo, 2013). Kendala tersebut sama yang dialami oleh Ibu Sujarwati sebagai pelaku usaha emping melinjo. Tidak heran memang, masa pandemi ini semua pelaku usaha mengalami kesulitan akibat penurunan omset besar-besaran (Angga Saputra Desti1, Triastuti Wuryandari2*), 2014).

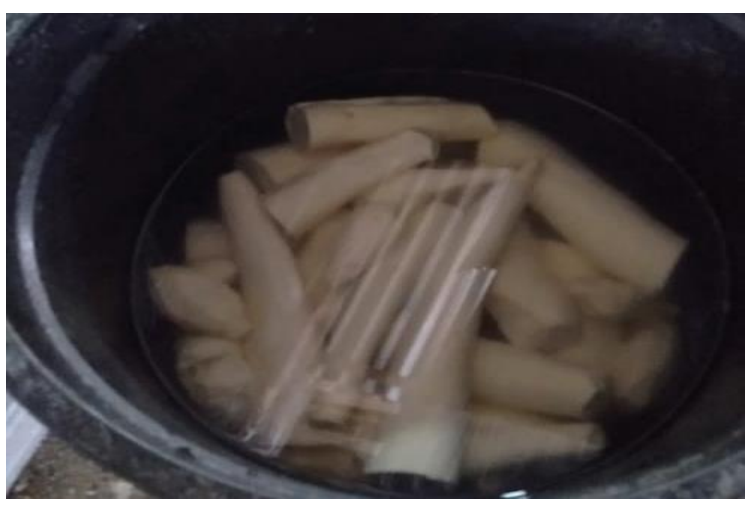

Gambar 2. Bahan dan Proses Produksi Gethuk

Tidak hanya itu saja kesederhanaan menjual aneka gethuk di pinggir jalan memang belum nampak kelihatan jelas dari kejauhan, hal serupa 

Keuangan untuk Memacu Perekonomian yang Lebih Baik- Nur Hudha Wijaya, Puspita Dewi Wulaningrum, Wisnu Kartika

DOI: https://doi.org/10.31004/abdidas.v2i3.319

dilakukan tim pengabdi yaitu membuat stiker untuk promosi dan banner, stiker kecil yang tertempel di setiap kardus aneka gethuk sebagai ciri tersendiri bahwa gethuk tersebut memiliki kualitas yang tidak kalah dari market yang sudah terkenal. Hal ini dibuktikan dengan meningkatnya penjualan di setiap harinya, karena pembeli akan lebih mudah mengira-ira untuk berhenti di pinggir jalan membeli gethuk tersebut, karena dari kejauhan sudah nampak jelas stiker besar yang tertempel di gerobak aneka gethuk.

Dengan demikian tujuan yang dicapai dalam progam ini adalah menerapkan teknologi dan keterampilan para pedagang atau pelaku UMKM agar memiliki keterampilan/kemampuan tentang penerapan pemanfaatan teknologi informasi dan pembukuan yang baik, sehingga para pelaku UMKM ini dapat memiliki pemahaman posisi usaha saat ini, bagaimana branding yang baik dan keuangan usahanya menjadi meningkat, kinerja usahanya berdasarkan laporan keuangan usaha yang dijalankan dan mampu bertahan dengan perkembangan jaman.

\section{METODE}

Metode yang digunakan adalah penyuluhan klasikal dan praktek lapangan, yang diawali memyampaikan materi kemudian dilanjutkan dengan praktik di ruang pelatihan, kemudian pelaku UMKM diminta mengaplikasikan langsung dengan usaha masing-masing. Hal tersebut dilakukan di Desa Wirokerten selama 1,5 bulan. Kegiatan yang dilakukan adalah 1) pendampingan pelatihan manajemen pembukuan, promosi/branding di media sosial dan (online/offline). Kedua kegiatan tersebut merupakan kelemahan pelaku UMKM, dengan demikian tim pengabdi membangkitkan semangat supaya mampu bertahan, karena pandemi ini banyak UMKM mengalami keguguran secara perlahan, kemudian selama pemantauan 1 bulan oleh tim pengabdi yang dilaporkan melalui sekretariat akan hasil pelaksanakan penerapan materi yang sudah disampaikan. Program pengabdian kepada masyarakat ini berjalan secara sistematis, terstruktur, dan terarah. Setelah proses aplikasi langsung observasi lapangan dan identifikasi permasalahan dapat dikumpulkan. Dari solusi yang ditawarkan kepada mitra, hasil cukup memuaskan dan mitra dapat memberikan masukan yang brilian.

\section{HASIL DAN PEMBAHASAN}

Pelaksanaan Pengabdian Masyarakat

1. Pembuatan Akun Sosial Media UMKM Gethuk 'Aneka Gethuk Mbak Rum'.

Program ini dilaksanakan bertujuan untuk menarik perhatian konsumen ketika ingin memesan kuliner dari mitra kami dan dapat menghubungi contact person yang telah tercantum. Kegiatan ini lumayan berhasil dalam menarik perhatian konsumen yang ingin membeli produk mitra. Untuk pembuatan akun media sosial dan melakukan promosi di akun media sosial individu semua anggota Kelompok 204 setiap 3x seminggu. Pembuatan akun media sosial dan promosi di akun individu hanya $1 \mathrm{x}$ dalam seminggu. Untuk faktor 
570 Peningkatan Produktifitas dan Pemasaran UMKM dengan Teknologi Informasi dan Manajemen Keuangan untuk Memacu Perekonomian yang Lebih Baik- Nur Hudha Wijaya, Puspita Dewi Wulaningrum, Wisnu Kartika

DOI: https://doi.org/10.31004/abdidas.v2i3.319

pendukung sendiri dengan adanya pandemi Covid-19 yang mengakibatkan banyak penjual produk melakukan kegiatan pemasaran secara online. Dengan hambatan produk mitra tidak tahan berhari-hari dan hanya bisa dilakukan sistem pre-order. Adapun akun instagram yang telah dibuat untuk mitra adalah @ anekagethuk.mbakrum.

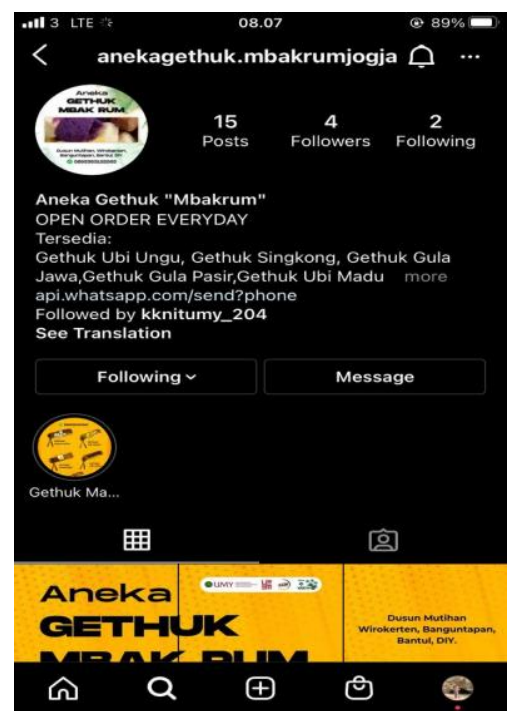

Gambar 3. Akun Sosial Media Aneka Gethuk

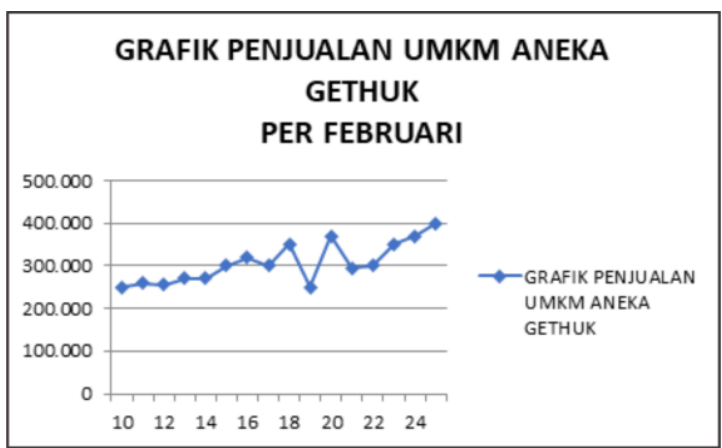

Gambar 4. Grafik Penjualan Gethuk

2. Pembuatan Akun Sosial Media UMKM Emping Melinjo 'Alvin Putra'.

Program ini dilaksanakan bertujuan menarik perhatian konsumen ketika ingin memesan kuliner jajanan dari mitra kami dan dapat menghubungi contact person yang telah tercantum. Kegiatan ini cukup berhasil dalam menarik perhatian konsumen yang ingin membeli produk mitra. Untuk pembuatan akun media sosial dan melakukan promosi di akun media sosial individu yang melibatkan semua anggota keluarga pemilik UMKM setiap $3 \mathrm{x}$ seminggu. Pembuatan akun media sosial dan promosi di akun individu hanya $1 \mathrm{x}$ dalam seminggu. Untuk faktor pendukung dengan adanya pandemi Covid-19 yang mengakibatkan banyak penjual produk melakukan kegiatan pemasaran secara online. Produk mitra harus dilakukan pre-order karena setiap hari hanya produksi dan produk yang sudah di packaging hanya tersedia dalam 4 hari sekali. Adapun akun Instagram yang telah dibuat untuk mitra adalah @empingmelinjo_alvinputra.

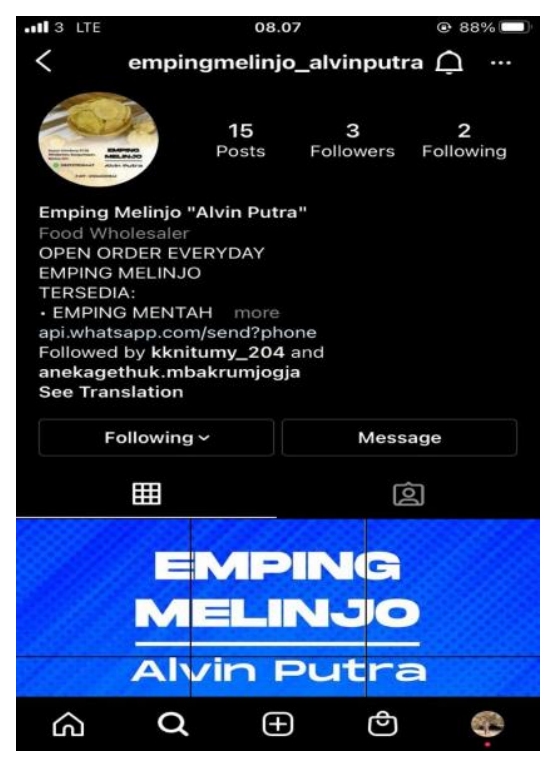

Gambar 5. Akun Sosial Media Emping Melinjo 
571 Peningkatan Produktifitas dan Pemasaran UMKM dengan Teknologi Informasi dan Manajemen Keuangan untuk Memacu Perekonomian yang Lebih Baik- Nur Hudha Wijaya, Puspita Dewi Wulaningrum, Wisnu Kartika

DOI: https://doi.org/10.31004/abdidas.v2i3.319

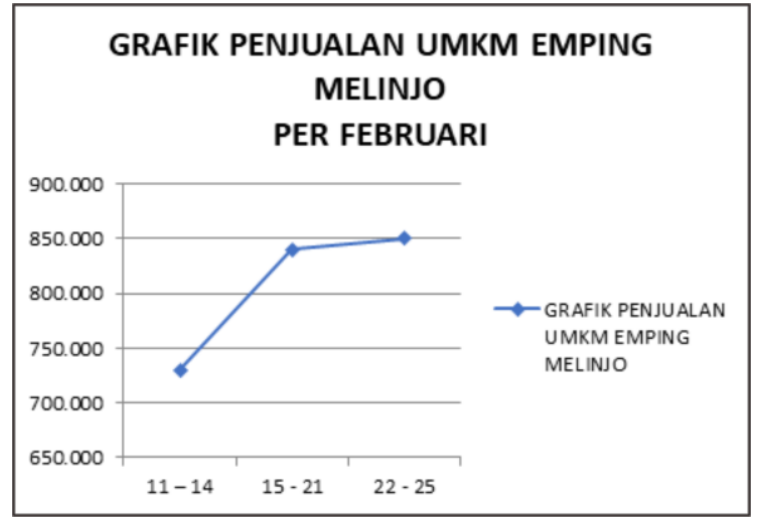

Gambar 6. Grafik Penjualan Emping Melinjo

Dari akun tersebut, penjualan cukup signifikan pada setiap harinya, karena banyak pembeli yang melihat story dari sosial media, tak lupa dihimbaukan kepada pelaku UMKM untuk selalu update produk yang dipasarkan.

Setiap tahapan selesai dilaksanakan, kegiatan akhir adalah evaluasi dari pendampingan yang sudah dilaksanakan, tidak menuntut kemungkinan belum sempurna pasti ada, tetapi usaha tidak memungkiri hasil. Kegiatan pengabdian ini bekerjasama dengan dua UMKM yaitu gethuk dan emping melinjo. Berdasarkan evaluasi lapangan seperti yang ditunjukkan pada grafik 4 dan 6 menunjukkan keberhasilan peningkatan penjualan, dengan perlahan pembukuan harian sudah tertata sesuai dengan arahan yang diberikan. Dengan demikian, mitra UMKM sudah mampu melakukan promosi/branding dengan memanfaatkan teknologi informasi serta melakukan pembukuan yaitu pencatatan dan pelaporan keuangan sesuai dengan standar sesuai urutan yang sudah disampaikan.

Atas ketercapaian pengabdian masyarakat ini diharapkan mampu menjadi percontohan
UMKM di wilayah Kelurahan Wirokerten, Kecamatan Banguntapan, Kabupaten Bantul Yogyakarta, sehingga UMKM yang lain mampu mengikuti dan melaksanakan hal serupa dalam usaha kecil yang dikelolanya. Hal ini bisa eksis tidak dimakan oleh jaman, karena dapat diketahui pembagian modal dan keuntungan serta memiliki database manajemen yang baik untuk melakukan review kembali letak kesalahan mendasar atas kekeliruan pengelolaan.

\section{UCAPAN TERIMA KASIH}

Terima kasih untuk Universitas Muhammadiyah Yogyakarta, melalui LP3M yang telah memberikan pendanaan pengabdian masyarakat ini sampai selesai, serta pihak yang mendukung baik internal maupun eksternal yang tidak dapat disebutkan satu persatu.

\section{SIMPULAN}

Pengabdian masyarakat yang telah berjalan dapat membantu memberikan sumbangsih untuk mengatasi salah satu kondisi pandemi ini yaitu dengan sistem promosi/pemasaran dan pembukuan yang berbasis IT, sehingga tujuan dapat tercapai dengan ditunjukkan hasil promosi oleh pelaku UMKM yang mengalami peningkatan pemasukan dengan UMKM emping melinjo 15\% dan aneka gethuk 20\% dengan hanya 1 bulan. Pengabdian masyarakat ini membekali keterampilan/ kemampuan tentang penerapan pemanfaatan teknologi informasi dan pembukuan, dengan pahamnya pelaku UMKM akan branding yang baik dan manajemen pembukuan keuangan yang 
572 Peningkatan Produktifitas dan Pemasaran UMKM dengan Teknologi Informasi dan Manajemen Keuangan untuk Memacu Perekonomian yang Lebih Baik- Nur Hudha Wijaya, Puspita Dewi Wulaningrum, Wisnu Kartika

DOI: https://doi.org/10.31004/abdidas.v2i3.319

baik, maka usaha menjadi meningkat, karena kinerja usahanya berdasarkan laporan keuangan usaha yang dijalankan dan mampu bertahan dengan perkembangan zaman.

\section{DAFTAR PUSTAKA}

Ahmad Farki, Imam Baihaqi, B. M. W. (2017). Pengaruh Online Customer Review dan Rating Terhadap Kepercayaan dan Minat Pembelian pada Online Marketplace di Indonesia. Jurnal Teknik ITS, 5(2).

Angga Saputra Desti1, Triastuti Wuryandari2*), S. (2014). Penentuan-komposisi-waktu-optimalproduk dengan metode taguchi. Jurnal Gaussian, 3(1), 11-20.

Aprih Santoso1, Teguh Ariefiantoro2, dan E. K. (2017). Pembukuan dalam Menunjang Kesuksesan Usaha Pengrajin Batik di Kecamatan Cepiring Kabupaten Kendal. EDIMAS, 8(2).

Ariani Kartika Suwignyo1, Justinus Andjarwirawan2, H. N. P. (n.d.). Perancangan dan Pembuatan Website Social Commerce Marketplace dengan Memanfaatkan API Media Sosial.

Beben Sutara. (2017). Optimalisasi Aplikasi Transaksi Penjualan Berbasis Web Menggunakan Framework Codeigniter (Studi Kasus: Rumah Makan Tirta Sandi Sumedang). Jurnal Informatika:Jurnal Pengembangan IT(JPIT), 2(1).

Endang Kartini Panggiarti. (2005). analisis-sikluspembukuan-akuntansi-koperasi-di-kotamagelang. 23(1).

Gary Hans1, Justinus Andjarwirawan2, S. R. (n.d.). 108072-ID-pembuatan-marketplacepenjualan-makanan.pdf.

Hudha-wijaya, N., Safitri, M., \& Kartika, W. (2020). Maintanance, Kalibrasi Dan Laporan Online Untuk Mewujudkan Pelayanan Prima Di Puskesmas. In Jurnal Abdidas (Vol. 1, Issue 3, pp. 119-124).

Qonita, R. A., Parnanto, N. H. R., \& Harisudin, M. (2016). Pengembangan Kemasan yang
Marketable Pada UKM Sofi dan Ukm Wida Di Desa Sendangagung Kecamatan Minggir Kabupaten Sleman. Seminar Nasional Universitas Islam Batik Surakarta, 64-75.

Sisilia Pujiatmo. (2013). studi-deskriptifpengelolaan-dan-pengembangan-usaha-padakecap-tiga-udang-di-madura. AGORA, l(1).

Sugiyanto, 2)Juni Trisnowati. (2018). Rancangbangun-mesin-perajang-kerupuk-jengkol untuk meningkatkan pendapatan UMKM. Engine, 2(2).

Wijaya, A. R. (n.d.). ANALISIS PERAN EVENT MARKETING WE STARMUSIC DALAM MENJAGA BRAND LOYALTY BIR BINTANG PILSNER. 